\title{
Aetiology, complications, and preventive measures of liver cirrhosis; Elobeid Hospital; West Sudan
}

\author{
AbdelSalam Mohamed Hamad Elfaki, MD
}

\begin{abstract}
:
Objectives: to determine the common causes of liver cirrhosis, identify the common complications, and to find the possible preventive measures of the disease at Elobeid Hospital; West Sudan.

Patients and method: This is a retrospective hospital based study. It was carried out in Elobeid Teaching Hospital. The medical and socio-demographic data of 61 patients who were admitted to the medical wards in the period from January 2006 to June 2007 with liver cirrhosis were retrieved and reviewed.

Results: Out of the 61 patients $38(62 \%)$ were males. The age of the patients

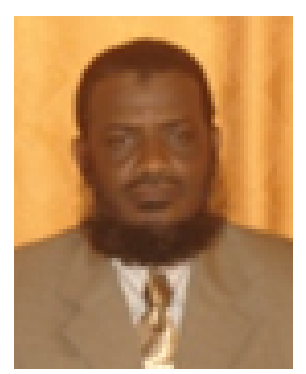
ranged from 17 to 80 years, with mean $( \pm \mathrm{SD})$ of $49 \pm 12.9$ years. Alcohol consumption was found to be the commonest cause of liver cirrhosis, followed by hepatitis B infection. Hepatitis $\mathrm{C}$ infection determined as a cause of liver cirrhosis in only one patient. Common complications included ascites (92\%), hepatic encephalopathy (19\%), portal hypertension (8\%), hepatocellular carcinoma (5\%), and spontaneous bacterial peritonitis (3\%). In the majority of patients, management was based on diuretics (furosemide and spironolactone) and dietary sodium restriction. Few patients received albumin infusion before therapeutic ascitic fluid aspiration. Silymarin in combination with multivitamins was commonly used in management of our patients.
\end{abstract}

Conclusion: Ethanol consumption and HBV infection were the commonest causes of liver cirrhosis in our patients. Religious and Health education to abandon ethanol intake and prohibit traditional practices that could predispose individuals to hepatitis B infection should be emphasized. Universal immunization with hepatitis B vaccine should be commenced to reduce the incidence of HBVrelated chronic liver diseases.

Key words: alcohol, hepatitis B, Hepatitis C, hepatocellular carcinoma.

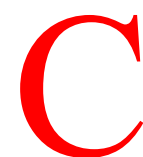

irrhosis of the liver is a histological diagnosis based on three essential criteria: diffuse disease, presence of fibrosis, and replacement of normal architecture by abnormal nodules ${ }^{1}$.

Whereas in Europe and North America high alcohol consumption is a very frequent cause of cirrhosis of the liver, in many Asian and Africans countries hepatitis $B$ virus is the most important etiologic agent ${ }^{2}$.

Ascites is the most common complication of liver cirrhosis ${ }^{3}$.

Bacterial infections, portal hypertension, hepatorenal syndrome, portopulmonary hypertension, hepatopulmonary hypertension,

Assistant Professor of Medicine,

Faculty of Medicine and health sciences,

Kordofan University, Elobeid, Sudan

Email:elfakioo9@yahoo.com hepatic hydrothorax, hepatocellular carcinoma (HCC) as well as alterations in cerebral blood flow are well described complications of cirrhosis ${ }^{4-7}$.

Restriction of sodium intake and enhancing sodium excretion by diuretics is the mainstay of the treatment of ascites ${ }^{8}$. Treating cirrhotic patients with oesophageal varices with propranolol significantly reduces the incidence of first variceal bleeding? Prophylaxis with norfloxacin $400 \mathrm{mg}$ daily significantly reduces the incidence of spontaneous bacterial peritonitis in high-risk cirrhotic patients ${ }^{10}$.

Elobeid Teaching Hospital in Kordofan state, Middle West of Sudan has a wide catch up area including different states (North Kordofan, West Kordofan, South Kordofan, parts of Darfour states). Most of the inhabitants work in agriculture, shepherds, 
and manual workers; hence most of the inhabitants are of low socio-economic classes.

\section{Patients and methods:}

This study is a hospital based study. It was carried out in Elobeid Teaching Hospital. The medical and socio-demographic data of 61 patients who were admitted to the medical wards in the period from January 2006 to June 2007 with liver cirrhosis were retrieved from the hospital records, reviewed and analyzed.

\section{Results:}

Out of 61 patients $38(62 \%)$ were males. The ages of the patients ranged from 17 to 80 years, with a mean $( \pm$ SD) of $49 \pm 12.9$ years (Fig.1)

Fig.1: Patient's age groups

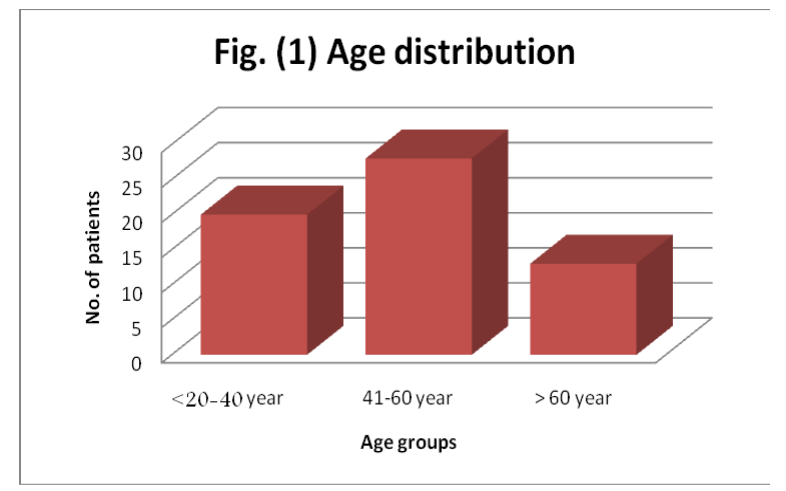

$57(92 \%)$ patients came from rural areas. $24(39 \%)$ patients have repeated hospital admissions with liver cirrhosis. Two patients received blood transfusion following bleeding from oesophageal varices. One patient received blood transfusion following haemorrhage due to snake bite and this is the only patient in whom screening for hepatitis $\mathrm{C}$ antibodies was positive. $14(23 \%)$ patients used to drink alcohol for average of 16.5 years. $17(27 \%)$ patients gave past history of jaundice and two of them are alcoholics. Screening for HBsAg in 23 patients was positive in $13(56.5 \%)$.

Clinical examination revealed jaundice in $17(27 \%)$, anaemia in12 (19\%), shrunken liver in 34(56\%), hepatomegaly $12(19 \%)$, splenomegaly $20(40 \%)$, and ascites in 55 $(92 \%)$ patients. The mean $( \pm$ SD) of systolic blood pressure was $117 \pm 12.5 \mathrm{mmHg}$, while mean $( \pm \mathrm{SD})$ of diastolic blood pressure was
$72 \pm 7.8 \mathrm{mmHg}$.

Ultrasound examination of the abdomen showed shrunken liver in 34 (56\%), normal size of liver with increased echogenicity in 5 (8\%), hepatomegaly with increased echogenicity in $17(28 \%)$ and enlarged nodular liver in $5(8 \%)$ patients. Massive ascites was demonstrated in 44 (72\%) patients, while in $17(28 \%)$ patients the ultrasound reports showed mild to moderate ascites.

The mean serum albumin ( \pm SD) was 2.9 $\pm 0.44 \mathrm{mg} / \mathrm{dl}$. The mean ascitic fluid albumin $( \pm \mathrm{SD})$ was $2 \pm 1.6 \mathrm{mg} / \mathrm{dl}$. Serum-ascitic fluid albumin gradient (SAAG) was calculated in 16 patient and the result is shown in table (1). Complications are shown in fig. (2).

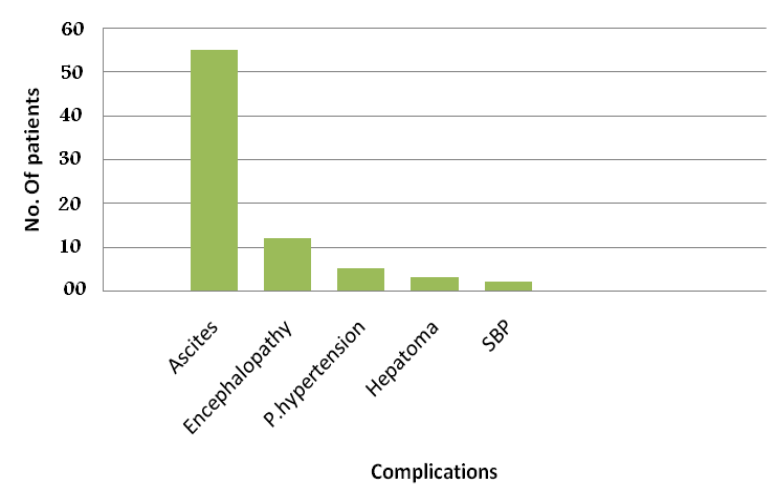

Fig.(2):complications of liver cirrhosis

Table (1): Serum-ascitic fluid albumin gradient (SAAG)

\begin{tabular}{l|lll} 
No & $\begin{array}{c}\text { Serum albumin } \\
(\mathrm{mg} / \mathrm{dl})\end{array}$ & $\begin{array}{c}\text { Ascitic fluid } \\
\text { albumin } \\
(\mathrm{mg} / \mathrm{dl})\end{array}$ & $\begin{array}{l}\text { SAAG } \\
(\mathrm{mg} / \mathrm{dl})\end{array}$ \\
\hline 1 & 2.4 & 2.0 & 0.4 \\
2 & 2.0 & 1.0 & 1.0 \\
3 & 3.0 & 2.5 & 0.5 \\
4 & 3.2 & 0.4 & 2.8 \\
5 & 2.6 & 0.4 & 2.2 \\
6 & 3.0 & 1.4 & 1.6 \\
7 & 2.8 & 0.6 & 2.2 \\
8 & 3.1 & 0.2 & 2.9 \\
9 & 2.3 & 0.8 & 1.5 \\
10 & 1.7 & 1.5 & 0.2 \\
11 & 3.0 & 1.0 & 2.0 \\
12 & 2.3 & 2.0 & 0.3 \\
13 & 2.8 & 1.8 & 1.0 \\
14 & 2.5 & 0.1 & 2.4 \\
15 & 2.8 & 0.17 & 2.63 \\
16 & 2.9 & 0.9 & 2.0 \\
\hline
\end{tabular}

Drugs used in of cirrhotic ascites include spironolactone $(85 \%)$ and furosemide $(75 \%)$. Silymarin was prescribed for $35(57 \%)$ cirrhotic patients. Oral lactulose was given for patients with hepatic encephalopathy. 


\section{Discussion:}

The main age $( \pm$ SD) of the patients was $49 \pm 12.9$ years and there was male preponderance with male: female ratio of 1.7:1. These findings are in line with some Nigerian reports ${ }^{11}$.

Unfortunately, similar to literature from West Africa ${ }^{12}$, most of the patients came late with very advanced decompensated liver cirrhosis. Local alcohol consumption and chronic hepatitis $\mathrm{B}$ infection seem to be the main causes of liver cirrhosis in this series. This fact differs from reports from European and Asian countries where alcohol consumption and hepatitis $\mathrm{C}$ infection dominate $^{13}$. HBV infection was found to be the commonest cause of liver cirrhosis in some African countries like Nigeria ${ }^{14}$.

In only one patient the liver cirrhosis was due to hepatitis $\mathrm{C}$ infection a fact which is quite different from reports from Pakistan in which hepatitis $\mathrm{C}$ is the leading cause of liver cirrhosis ${ }^{15}$. No obvious cause to explain that.

However, the initial paucity of testing for hepatitis $\mathrm{C}$ virus might have played an important role in our results.

In $26(43 \%)$ patients the systolic blood pressure was at the lower limits of normal while the mean diastolic blood pressure was $72 \pm 7.8 \mathrm{mmHg}$, this is similar to what is mentioned in the literature ${ }^{16}$.

Splenomegaly was detected in 20(33\%) patients and this is similar to other reports ${ }^{17}$

Ascites was detected in $95 \%$ of patients ranging from mild to massive ascites as mentioned in the literature ${ }^{18}$

In the majority of patents in whom the Serum Ascitic fluid Albumin Gradient (SAAG) was calculated Table (1), it was greater than $1.1 \mathrm{~g} / \mathrm{dl}$ supporting the assumption that the ascites in these patients is due to liver cirrhosis ${ }^{19}$

The incidence of HCC in patients with liver cirrhosis is estimated to be 3 to $5 \%$ per year ${ }^{20}$ Only three patients of those included in our study proved to have HCC (Fig.2). The low incidence may be due to lack of facilities for the diagnosis of early stages of the tumour.

Missing the correct diagnosis may explain the low existence $(3 \%)$ of Spontaneous Bacterial Peritonitis (SBP) in our patients when compared with the $7-23 \%$ reported elsewhere ${ }^{21}$.

One patient was found to have rightsided pleural effusion (hepatic hydrothorax). This complication seems to be a relatively uncommon, although in some references the estimated prevalence is $5-12 \%$ in patients with cirrhosis of the liver ${ }^{22}$. Similar to reports, portal hypertension is evident in all patients with liver cirrhosis on abdominal ultrasound examination $^{25}$. The rate of variceal bleeding is approximately $10-30 \%$ per year ${ }^{23}$. Only one of our patients had bleeding due to varices.

Although hepatic encephalopathy represents a potentially reversible decrease ${ }^{24}$, nine of the twelve patients (19\%) who presented with encephalopathy (Fig. 2) died in spite of supportive measures

Conclusion: Alcohol and hepatitis B infection are the main causes of liver cirrhosis in our patients, therefore, health education to prohibit traditional practices that could predispose individuals to hepatitis B infection should be emphasized. Universal immunization with hepatitis $B$ vaccine should be commenced to reduce the incidence of HBV-related chronic liver diseases. Alcohol intake problem should be handled by the local health advisors and religious leaders.

\section{References:}

1. Anand BS. Cirrhosis of the liver. Western journal of Medicine 1999; 171(2):110-115.

2. Iwamura K. Liver cirrhosis in Asia and Africa. Z Gastroenterol 1983; 21(11): 637-43.

3. Benjaminov FS. The Pathophysiology of ascites formation in cirrhosis of the liver. Harefuah. 2002;141(8):721.

4. Farkas M A, Udvardy M, Tornai I. Bacterial infections in liver cirrhosis. Orv Hetil 2007; 148(9): 387-95.

5. Menon KV, Kamath PS. Regional and systemic hemodynamic disturbances in cirrhosis. Clin liver Dis 2001; 5(3):617-627.

6. Lee RF, Glenn TK, Lee SS. Cardiac dysfunction in cirrhosis. Best Pract Res Clin Gastroenterol 2007; 21(1): 125-40.

7. Maria C, Tommas S, Alfredo V et al. Rate of incidence of hepatocellular carcinoma in patients with compensatory viral cirrhosis. Cancer 2000; 85 (10):2132-2137.

8. Schouten J, Michielsen PP. Treatment of cirrhotic ascites. Acta Gastroenterol Belq 2007; 70(2): 217-22.

9. Gross M, Zoller WG. Medical prophylaxis of haemorrhage from oesophageal varices in patients 
with liver cirrhosis. Eur J Gastroenterol Hepatol 1997; 9(6):603-12.

10. Sandh BS, Gupta R, Sharma J et al. Norfloxacin and cisapride combination decreases the incidence of spontaneous bacterial peritonitis in cirrhotic ascites. J Gastroenterol Hepatol 2006; 21(10):1634.

11. Lesi OA, Kehinde MO, Anomneze EE. Chronic liver disease in Lagos: a clinicopathollogical study. Niger Postgrad Med J. 2004; 11(2):91-6.

12. Ndububa DA, Ojo OS, Aladeqbaiye AO et al. Liver cirrhosis: Child-Pugh grading of cases in Nigeria. Trop Doct. 2005; 35 (3): 169-71.

13. Khokhar N, Niazi SA. Chronic liver disease related mortality pattern in Northen Pakistan. J Coll Physician Surg Pak 2003; 13(9):495-7.

14. Bojuwoye BJ. The burden of viral hepatitis in Africa. West Afr J Med 1997; 16: 198-203.

15. Magsood S, Saleem A, Igbal A et al. Precipitating factors of hepatic encephalopathy: experience at Pakistan Institute of Medical Sciences Islamabad. J Ayub Med Coll Abbbottabad 2006; 18 (4): 58-62.

16. Kim MY, Baik SK. Cirrhotic Cardiomyopathy, Korean J Hepatol 2007; 13(1):20-6.

17. Seebaran AR, O'keefe SJ, Akerman BS. Pattern of cirrhosis in natal Indians. S Afr Med J 1988; 74(12):
622-4.

18. Sandhu B.S, Sanyal A.J. Management of ascites in cirrhosis. Clin Liver Dis 2005; 9(4): 715.

19. Khan FY. Ascites in the state of Gatar: etiology and diagnostic value of ascitic fluid analysis. Singapore Med J 2007; 48(5):434-9.

20. Trinchet JC, Beaugrand M. Alcoholic liver cirrhosis. Screening for hepatocellular carcinoma in liver cirrhosis. Presse Med 2001; 30(23): 1164-9.

21. Lach J, Rimola A, Navasa M, et al. Incidence and predictive factors of first episode of SBP in cirrhosis with ascites: relevance of ascitic protein concentration. Hepatology 1992; 16: 724-727.

22. Anastasios R, Nikiphoros P, Gerassimo J et al. Hepatic hydrothorax: Pathophysiology, diagnosis and management. J Gastroenterol Hepatol 2007; 22(9): 1388-1393.

23. Roberto J, Guadalupe G, Jaime B et al. BetaBlockers to prevent gastro-oesophageal varices in patients with cirrhosis. N Eng J Med 2005; 353 (21):2254-2261.

24. Joel J. Mayam S. Cirrhosis and chronic liver disease: Part 1. Complications and treatment. American Family Physician 2000; 74(5): 781-785. 